\title{
Flavor Components of Mideoduck (Styela clava)
}

\author{
Byeong-Dae Choi*, Bong-Se $\mathrm{Oh}^{1}$ and Seok-Joong Kang ${ }^{2}$
}

Department of Seafood Science and Technology/nstitute of Marine Industry, Gyeongsang National University, Tongyeong 650-160, Korea ${ }^{1}$ National Fisheries Research \& Development Institute, Busan 619-900, Korea

${ }^{2}$ Department of Marine Life Science/nstitute of Marine Industry, Gyeongsang National University, Tongyeong 650-160, Korea

Received August 16, 2010 / Accepted October 27, 2010

\begin{abstract}
The flavor extracts of Mideoduck muscle and its juices were concentrated by simultaneous distillation and extraction (SDE) and solid-phase microextraction (SPME) methods. Each component present in the extracts was identified with GC and GC-MS by the $n$-paraffin hydrocarbon retention index and standard MS library data system. By SDE, $371.3 \mu \mathrm{g} / \mathrm{g}$ of hexanal, $80.1 \mu \mathrm{g} / \mathrm{g}$ of 1-tridecanol, $72.1 \mu \mathrm{g} / \mathrm{g}$ of (Z)-4,5-dimethylhex-2-en-4-ol with other alcohols, aldehydes and acids were present in the flavor extracts, with the alcohols having the highest composition and being the most important factor in Mideoduck muscle flavor. By SPME, 9 alcohols, 1 acid, 1 aldehyde, 1 hydrocarbon, 1 ester, 1 amine and 2 ketones were detected in the extracts, with alcohol such as 1-nonanol, 1-decanol and 1-tridecanol as the major components. In SPME, the muscle sample, consisting of $31.6 \mu \mathrm{g} / \mathrm{g}$ of 1-nonanol, 20.3 $\mu \mathrm{g} / \mathrm{g}$ of (E)-2-butenedioic acid dibutylester, and $26.7 \mu \mathrm{g} / \mathrm{g}$ of heptadecanoic acid made up the $62.1 \%$ of total flavor extracts of Mideoduck muscle. The results of the SPME methods were similar to the composition of the raw material flavor of the sample even at a low concentration.
\end{abstract}

Key words : Mideoduck, flavor, simultaneous distillation and extraction (SDE), solid-phase microextraction (SPME)

\section{서 론}

미더덕(Styela clava)은 척색동물문 미색동물아문에 속하는 해양생물로 세계에는 약 2,300 여종이 자생하고 있는 것으로 알려져 있으며[22], 독특한 향과 맛으로 인하여 우리나라에서 만 식품소재로 이용되고 있다. 1995년부터 2년간 수행된 미더 덕 양식 가능성에 관한 농수산특정연구과제의 하나로 시작되 어 1998년부터 굴과 진주담치 등의 양식대체 종으로 허가 받 기에 이르렀다. 최근 건강식품의 선호현상 때문에 미더덕의 소비가 증가하고 있으며 생산량도 매년 증가하면서 어민의 소득증대에 기여하고 있다. 통영을 비롯한 거제, 고성, 마산 등 남해안에서 주로 생산되고 있으며, 3월부터 7월 사이가 생 산량이 가장 많은 시기이다. 미더덕의 소비 형태는 주로 찜이 나 된장찌개 등의 재료로 이용되며, 그 밖에 횟감용으로 4 5월 경에 채취된 것이 이용되고 있다.

웰빙 트렌드와 맞물려 소위 자연조미료, 천연조미료를 표방 하는 제품들이 출시되면서 조미료시장의 제 3 세대 혁명이 시 작됐다. 1 세대 발효조미료, 2 세대 종합조미료에 이어 3 세대 천연조미료 시장이 증가하고 있다. 1 세대 조미료는 미원을 위 시한 발효조미료로 대변된다. 1960년대 개발된 미원의 발효조 미료는 맛을 내주는 아미노산인 글루타민산을 발효방식으로

*Corresponding author

Tel : +82-55-640-3173, Fax : +82-55-648-2038

E-mail : bdchoi@gnu.ac.kr
증강시킨 것으로 맛의 혁명이라고 일컬어질 정도로 주부들에 게 선풍적인 인기를 끌었으나 식문화의 고급화로 가정용 수요 는 매년 줄어들고 있다[21]. 화학조미료를 많이 섭취하게 되면 어린이에게 뇌손상, 천식유발 등이 우려되며 최근 증가되고 있는 아토피 질환에도 영향을 줄 수 있으며, 또한 MSG를 과다 섭취하면 두통, 메스꺼움, 가슴통증, 저림, 안면홍조, 졸음, 무 력감, 안면근육 경직 등의 부작용이 발생할 수 있다는 보고가 발표되고 있다[2]. 이에 따라 2008년을 기점으로는 천연조미료 시장이 확대되고 있다. 건강과 식품안전을 동시에 만족하려는 소비자의 심리 덕분으로 인공적인 화학첨가물을 배제했다는 점에서 '조미료의 진화'로 볼 수 있다.

최근 미더덕에 대한 관심이 높아지면서 계절에 따른 영양성 분의 비교[16], 오만둥이 된장찌개의 향기성분[9,10], 미더덕 함유 어묵의 품질특성[18], 암세포주에 대한 미더덕 추출물의 세포독성 효과[12], 아세톤 추출물이 산화적 DNA 손상억제 영향[23], 미더덕 추출물의 항산화 및 항암효과[13], 주름 미더 덕 추출물의 항산화력[14], 미더덕 껍질로부터 glycosaminoglycans의 추출[1] 등 많은 연구가 이루어지고 있다. 특히 미더덕이 갖고 있는 기능성 성분에 대한 관심이 높아지 면서 기능성 식품소재로서의 가치가 높아지고 있다. 따라서 본 연구에서는 미더덕 체액을 천연 조미료로 이용할 경우 풍 미의 주성분이 되는 향기성분에 대한 연구가 없어 이에 대한 자료를 얻고자 하였다. 


\section{재료 및 방법}

\section{재료}

본 실험에 사용한 미더덕(Styela clava)은 2007년 1월, 3월, 5 월 경남 거제시 성포에서 채취하여 $20 \mathrm{~kg}$ 으로 소포장한 후 $-24^{\circ} \mathrm{C}$ 의 냉동고에 저장하여 두고 각 항목의 분석을 위하여 재 료를 흐르는 수돗물에서 해동 후 실험에 사용하였다.

\section{Simultaneous Steam Distillation and Extraction (SDE)에 의한 향기성분의 추출 \\ 초퍼(copper)로서 마쇄한 신선한 미더덕 육 및 체액 $100 \mathrm{~g}$ 에 탈이온수 $900 \mathrm{ml}$ 와 내부표준물질(cyclohexanol, $140.5 \mu \mathrm{g}$ )을 첨가한 다음 $\mathrm{SDE}$ 장치에서 ether를 추출용매로 $2 \mathrm{hr}$ 추출 농축 하였다[17]. 추출된 향기성분은 KD (Kuderna-Danish Sample Concentrators) 농축기로 서서히 용매를 제거하여 약 $1 \mathrm{ml}$ 가 되도록 하여 GC 및 GC-MS로 동정하였다.}

Solid-Phase Microextraction (SPME)에 의한 향기성
분의 추출

SPME 장치(Manual type, Supelco Inc., Bellefonte, PA, USA)에, 흡착용 fiber는 polydimethylsiloxane/divinylbenzene (PDMS/DVB, $65 \mu \mathrm{m}$ coating thickness)를 사용하였 다. 시료 일정량과 내부표준물질(cyclohexanol, $70.3 \mu \mathrm{g})$ 을 첨 가한 다음 $20 \mathrm{ml}$ 의 headspace glass vial (Supelco Inc., Bellefonte, PA, USA)에 넣고 aluminum crimp seal $(20 \mathrm{~mm}$, open center)과 polytetrafluoroethylene (PTEE)/silicone septum $(60 \mathrm{mils})$ 으로 밀봉한 후 $40^{\circ} \mathrm{C}$ 에서 30 분간 fiber를 vial 내에서 노출시켜 휘발성 화합물을 흡착시켰다.

\section{향기성분의 분석}

미더덕 육 및 체액으로부터 채취한 향기물질의 조성은 capillary column (Omegawax-320, $30 \mathrm{~m} \times 0.32 \mathrm{~mm}$ i.d., 0.25 $\mu \mathrm{m}$ thickness, Supelco, St. Louis. MO, USA)과 FID를 장착한 GC (Shimadzu 17A, Kyoto, Japan)로 분석하였다. Injector $250^{\circ} \mathrm{C}$, detector $260^{\circ} \mathrm{C}$, carrier gas (He)는 $1 \mathrm{ml} / \mathrm{min}$ 로 유지하 였고, split ratio는 100:1로 하였다. SPME법에 의해 추출된 시 료 성분은 직접 $\mathrm{GC}$ 에 fiber를 탈착시켜 주입하였다. 분석조건 은 column 온도를 최초 5 분간은 $40^{\circ} \mathrm{C}$ 로 유지하다가 분당 $3^{\circ} \mathrm{C}$ 씩 상승시켜 $240^{\circ} \mathrm{C}$ 에 도달한 다음 40 분간 유지시켰다.

\section{향기성분의 동정 및 정량}

GC profile에 나타난 각 향기성분의 peak에 해당하는 휘발 성화합물의 linear retention indices를 결정하기 위하여 탄화 수소(n-paraffins, $\mathrm{C}_{5}-\mathrm{C}_{25}$, Alltech Associates, USA)를 표준물 질로 사용하였고, 시료의 향기성분을 분석할 때와 동일한 조 건으로 GC에 주입하여 C5-C25의 표준 머무름 시간을 구하였
다. 시료의 GC profile상에 나타난 각 향기성분의 머무름 시간 과 표준 탄화수소와의 머무름 시간을 비교하여 향기성분의 retention index (RI)를 구하였다[3]. 각 휘발성 화합물에 대한 잠정적인 동정은 retention index 및 standard MS library data (Wiley 275K, Hewlett-Packard Co., USA)에 의하였으며, 휘발 성 화합물의 함량은 내부표준물질을 이용하여 상대적 함량으 로 환산하였다(factor $=1, \mu \mathrm{g} / \mathrm{g}$ ).

\section{결과 및 고찰}

\section{향기성분의 분리 및 동정}

미더덕 육 및 체액에 함유된 성분 중 가열에 의해 생성되는 향기성분을 분석하기 위하여 $100^{\circ} \mathrm{C}$ 에서 일정시간 추출·농축 하는 simultaneous distillation and extraction $(\mathrm{SDE})$ 를 이용하 여 육으로부터 34 및 16성분을 동정하여 Fig. 1, 2 및 Table 1,2 에 각각 나타내었고, 미더덕 육 및 체액이 갖는 headspace 를 얻기 위하여 solid-phase microextraction (SPME)를 이용하 여 육으로부터 37 및 20성분을 동정하여 Fig. 3, 4 및 Table 3,4 에 각각 나타내었다. 총 함량은 cyclohexanol을 기준으로 $\mathrm{SDE}$ 에 의해 육 및 체액으로부터 797.8 및 $859.3 \mu \mathrm{g} / \mathrm{g}$ 이었고, $\mathrm{SPME}$ 에 의해 육 및 체액으로부터 126.5 및 $115.7 \mathrm{\mu g} / \mathrm{g}$ 이었다. 이들 화합물을 group별로 분류하면 SDE 추출 육의 경우 alcohol류 17종, acid류 6종, aldehyde류 5종, hydrocarbon류 6종 으로 구성되었으며, aldehyde류가 가장 높은 함량이었고, alcohol류가 그 다음이었다. SDE 추출 체액의 경우 alcohol류 20종, acid류 4종, aldehyde류 6종, hydrocarbon류 7종으로 구 성되었으며, aldehyde류가 가장 높은 함량이었고, alcohol류 가 그 다음으로 육과 매우 유사하였다. SPME 추출 육의 경우 alcohol류 9종, acid류 1종, aldehyde류 1종, hydrocarbon류 1종, ester 1종, amine 1종, ketone 2종으로 구성되었으며, alcohol류가 가장 높은 함량이었고, acid 및 ester류가 그 다음이었 다. SPME 추출 체액의 경우 alcohol류 9종, acid류 2종, aldehyde류 3종, hydrocarbon류 2종, ester 1종, amine 1종, ketone 2종으로 구성되었으며, aldehyde류가 가장 높은 함량이었고, alcohol류가 그 다음이었다.

SDE 추출 육의 향기성분(Fig. 1 및 Table 1)에서는 alcohol 화합물 중에서는 (Z)-4,5-dimethylhex-2-en-4-ol의 함량이 가 장 높았고, 1-octanol, 1-nonanol, 1-tridecanol, 9,12,15-octadecatrien-1-ol 등이 동정되었으나, 이들 alcohol류는 역치가 높아 시료 향의 발현에 영향을 미치지 못하나 미더덕 육의 경우 그 함량이 다른 화합물보다 높아 미더덕 향의 형성에 크게 기여한 것으로 여겨진다. Jeong 등[9]에 의하면 가열조리 된 오만둥이 된장찌개에서의 주성분인 decenol, 2,6-dimethylheptanol 및 octanol 등이 오만둥이에서 유래되었고, 된장 가열 후에는 benzeneacetaaldehyde가 주된 성분으로 카르보 닐 화합물과 함질소화합물이 증가되었다고 하여 미더덕 육으 


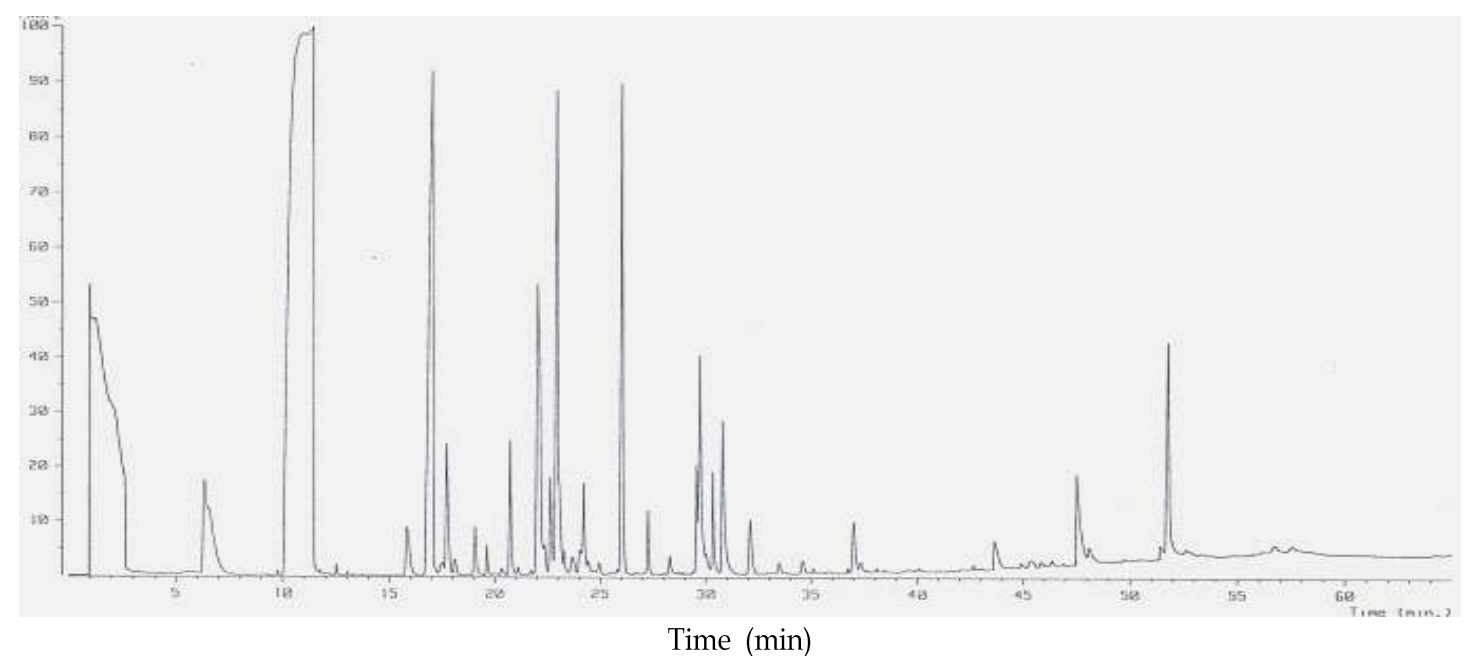

Fig. 1. Total ion chromatogram of whole volatile components of Mideoduck muscle by steam distillation and extraction (SDE).

Table 1. Whole volatile compounds of Mideoduck muscle by steam distillation and extraction (SDE)

\begin{tabular}{|c|c|c|c|}
\hline RT & R.I. $^{\mathrm{a}}$ & Conc. $^{b}$ & Compounds name ${ }^{c}$ \\
\hline 2 & $<800$ & 26.1 & 3-Ethyl-2-pentene \\
\hline 3 & 869 & 371.3 & Hexanal \\
\hline 5 & 1198 & 11.5 & 1-Octanol \\
\hline 6 & 1230 & 72.1 & (Z)-4,5-Dimethylhex-2-en-4-ol \\
\hline 7 & 1260 & 23.6 & 1-Nonanol \\
\hline 9 & 1270 & 2.1 & 1-Decanol \\
\hline 10 & 1300 & 3.8 & 1-Undecanol \\
\hline 13 & 1353 & 8.5 & 5-Decen-2-ol \\
\hline 14 & 1393 & 39.8 & 1-Dodecene \\
\hline 15 & 1394 & 0.8 & 1-Dodecanol \\
\hline 16 & 1405 & 16.2 & 2,4-Decadienal \\
\hline 17 & 1416 & 29.4 & Tridecanal \\
\hline 18 & 1421 & 80.1 & 1-Tridecanol \\
\hline 20 & 1434 & 0.7 & Tetradecanal \\
\hline 21 & 1450 & 2.5 & 1-Tetradecanol \\
\hline 22 & 1460 & 0.6 & 1,13-Tetradecanol \\
\hline 23 & 1464 & 1.5 & 2-Pentadecen-4-yne \\
\hline 25 & 1517 & 20.6 & 2,6-Bis(1,1-dimethylethyl)-4-methylphenol \\
\hline 28 & 1561 & 4.8 & Tetradeca-4,9-dien-1-ol \\
\hline 30 & 1593 & 1.0 & 4-Hexadecen-6-yne \\
\hline 31 & 1634 & 1.8 & 5-Octadecyne \\
\hline 32 & 1939 & 18.6 & 9,12-Octadecadien-1-ol \\
\hline 33 & 1649 & 3.5 & (Z)-3-Heptadecen-5-yne \\
\hline 34 & 1660 & 4.2 & $9,12,15$-Octadecatrien-1-ol \\
\hline 35 & 1674 & 10.6 & 17-Octadecen-14-yn-1-ol \\
\hline 36 & 1714 & 3.0 & Hexadecanal \\
\hline 39 & 1757 & 0.7 & Cycloheptadecanol \\
\hline 40 & 1795 & 0.6 & Dodecanoic acid \\
\hline 41 & 1867 & 0.2 & (Z)-9-Octadecen-1-ol \\
\hline 44 & 2081 & 0.1 & Tetradecanoic acid \\
\hline 46 & 2204 & 3.2 & Hexadecanoic acid \\
\hline 47 & 2222 & 10.3 & Heptadecanoic acid \\
\hline 48 & 2326 & 0.2 & (Z)-9-Octadecenoic acid \\
\hline 49 & 2337 & 23.8 & Octadecanoic acid \\
\hline
\end{tabular}

${ }^{\mathrm{a}}$ Retention index on Supelcowax $320^{\mathrm{TM}}(30 \mathrm{~m} \times 0.25 \mathrm{~mm}$ i.d. $\times 0.25 \mu \mathrm{m}$ thickness, Supelco Co., USA) column.

${ }^{b}$ Concentration $(\mu \mathrm{g} / \mathrm{g})$ of each compound was calculated as a relative content to cyclohexanol put in sample by extraction method (140.5 $\mu \mathrm{g}$ ) (factor=1.0).

${ }^{\mathrm{c}}$ These compounds were tentatively identified by MS Library data (Wiley $275 \mathrm{~K}$. Hewlett-Packard Co., USA). 


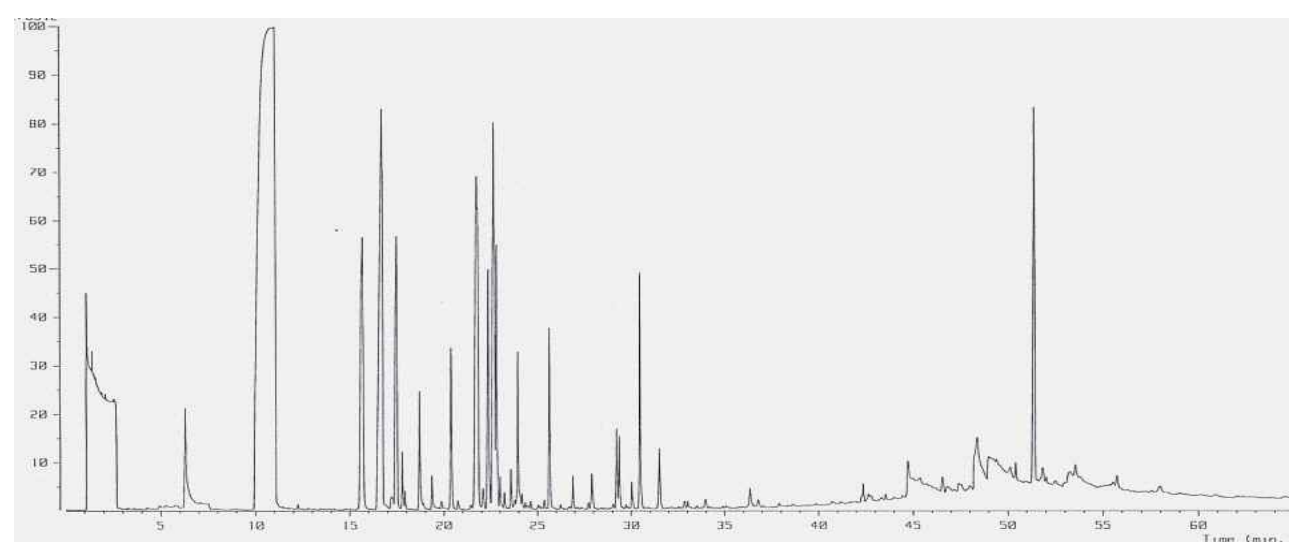

Time (min)

Fig. 2. Total ion chromatogram of whole volatile components of Mideoduck fluid by steam distillation and extraction (SDE).

Table 2. Whole volatile compounds of Mideoduck fluid by steam distillation and extraction (SDE)

\begin{tabular}{|c|c|c|c|}
\hline RT & R.I. $^{\mathrm{a}}$ & Conc. $^{b}$ & Compounds name $^{\mathrm{c}}$ \\
\hline 2 & $<800$ & 24.3 & 3-Ethyl-2-pentene \\
\hline 3 & 869 & 365.4 & Hexanal \\
\hline 5 & 1198 & 43.2 & 1-Octanol \\
\hline 6 & 1230 & 78.2 & (Z)-4,5-Dimethylhex-2-en-4-ol \\
\hline 7 & 1260 & 40.3 & 1-Nonanol \\
\hline 8 & 1265 & 2.4 & 2-Furanmethanol \\
\hline 9 & 1270 & 1.5 & 1-Decanol \\
\hline 10 & 1300 & 4.1 & 1-Undecanol \\
\hline 11 & 1318 & 1.4 & (E)-4-methyl-3-decen-2-ol \\
\hline 12 & 1336 & 8.6 & Cyclodecene \\
\hline 13 & 1353 & 0.9 & 5-Decen-2-ol \\
\hline 14 & 1393 & 63.5 & 1-Dodecene \\
\hline 15 & 1394 & 1.8 & 1-Dodecanol \\
\hline 16 & 1405 & 19.6 & 2,4-Decadienal \\
\hline 17 & 1416 & 31.7 & Tridecanal \\
\hline 18 & 1421 & 23.4 & 1-Tridecanol \\
\hline 19 & 1429 & 1.1 & Cyclodecanol \\
\hline 20 & 1434 & 1.9 & Tetradecanal \\
\hline 21 & 1450 & 2.2 & 1-Tetradecanol \\
\hline 22 & 1460 & 8.2 & 1,13-Tetradecadienel \\
\hline 23 & 1464 & 0.8 & 2-Pentadecen-4-yne \\
\hline 25 & 1517 & 9.8 & 2,6-Bis(1,1-dimethylethyl)-4-methylphenol \\
\hline 28 & 1561 & 1.3 & Tetradeca-4,9-dien-1-ol \\
\hline 29 & 1563 & 1.2 & 4-Hexadecen-6-yne \\
\hline 31 & 1634 & 3.6 & 5-Octadecyne \\
\hline 32 & 1939 & 3.4 & 9,12-Octadecadien-1-ol \\
\hline 33 & 1649 & 0.9 & (Z)-3-Heptadecen-5-yne \\
\hline 34 & 1660 & 32.6 & $9,12,15$-Octadecatrien-1-ol \\
\hline 35 & 1674 & 13.2 & 17-Octadecen-14-yn-1-ol \\
\hline 36 & 1714 & 3.2 & Hexadecanal \\
\hline 38 & 1744 & 0.2 & 17-Octadecadien-1-ol \\
\hline 39 & 1757 & 0.3 & Cycloheptadecanol \\
\hline 41 & 1867 & 0.4 & (Z)-9-Octadecen-1-ol \\
\hline 43 & 2045 & 0.6 & Tridecanoic acid \\
\hline 45 & 2120 & 0.1 & Pentadecanoic acid \\
\hline 47 & 2222 & 4.2 & Heptadecanoic acid \\
\hline 50 & 2337 & 59.8 & Octadecanoic acid \\
\hline
\end{tabular}

${ }^{\mathrm{a}}$ Retention index on Supelcowax $320^{\mathrm{TM}}(30 \mathrm{~m} \times 0.25 \mathrm{~mm}$ i.d. $\times 0.25 \mu \mathrm{m}$ thickness, Supelco Co., USA $)$ column.

${ }^{b}$ Concentration $(\mu \mathrm{g} / \mathrm{g})$ of each compound was calculated as a relative content to cyclohexanol put in sample by extraction method $(140.5 \mu \mathrm{g})$ (factor=1.0).

${ }^{c}$ These compounds were tentatively identified by MS Library data (Wiley 275 K. Hewlett-Packard Co., USA). 
로부터 알코올류의 증가는 미더덕 특성에서 기인되는 것으로 여겨진다. Kusaka 등[15]은 멍게 향기성분을 분석한 결과 멍게 특유의 향기성분으로서 n-octanol, n-decenol, n-decadienol 등 의 포화 및 불포화 alcohol이 주성분이라고 하였고, Fujimoto 등 [8]은 멍게의 독특한 향기성분들은 t-2,c-7-decadien-1-ol 및 이들의 이성체 등을 포함하는 불포화 1 급 alcohol이 주성분으 로 근육 및 내장에 존재하는 무취의 alkyl sulfate가 내장 중의 alkylsulfohydrolase에 의해 분해되어 생성된다고 하였다. 따 라서 미색류의 주된 향기성분인 알코올류의 생성은 육에 함유 된 성분의 분해와 가열에 의하여 생성되는 것으로 판단된다.

$\mathrm{SDE}$ 추출 체액의 향기성분(Fig. 2 및 Table 2)에서도 1-octa$\mathrm{nol}(43.2 \mathrm{\mu g} / \mathrm{g})$ 을 비롯한 1-nonanol $(40.3 \mu \mathrm{gg} / \mathrm{g})$ 등 육과 매우
비슷한 구성을 나타내었고, Choi와 Ho [7] 등에 의하면 멍게 향기성분의 중성 획분에서 동정된 alcohol은 전체 향기성분의 약 $38 \%$ 이상을 차지하여 이들이 멍게 향의 주성분인 것으로 보고하였다. 특히 육 추출물에서는 동정되지 않았던 2-furanmethanol이 검출되었다. 2-Furanmethanol은 타는 냄새와 쓴맛을 내며, 당을 가공하는 중에 생성되는 물질이므로[20], 체액에 함유된 아미노산과의 반응으로 생성된 것으로 여겨진 다. 육에서의 방향족 화합물인 phenol의 함량은 $20.6 \mu \mathrm{g} / \mathrm{g}$ 이 었으나, 체액으로부터는 $9.8 \mu \mathrm{g} / \mathrm{g}$ 으로 낮은 함량으로 존재하 는 것으로 나타났으며, 바람직하지 못한 향의 성분으로 알려 져 있다[3].

Aldehyde 화합물 중에서는 hexanal이 $365.4 \mu \mathrm{g} / \mathrm{g}$ 으로 가

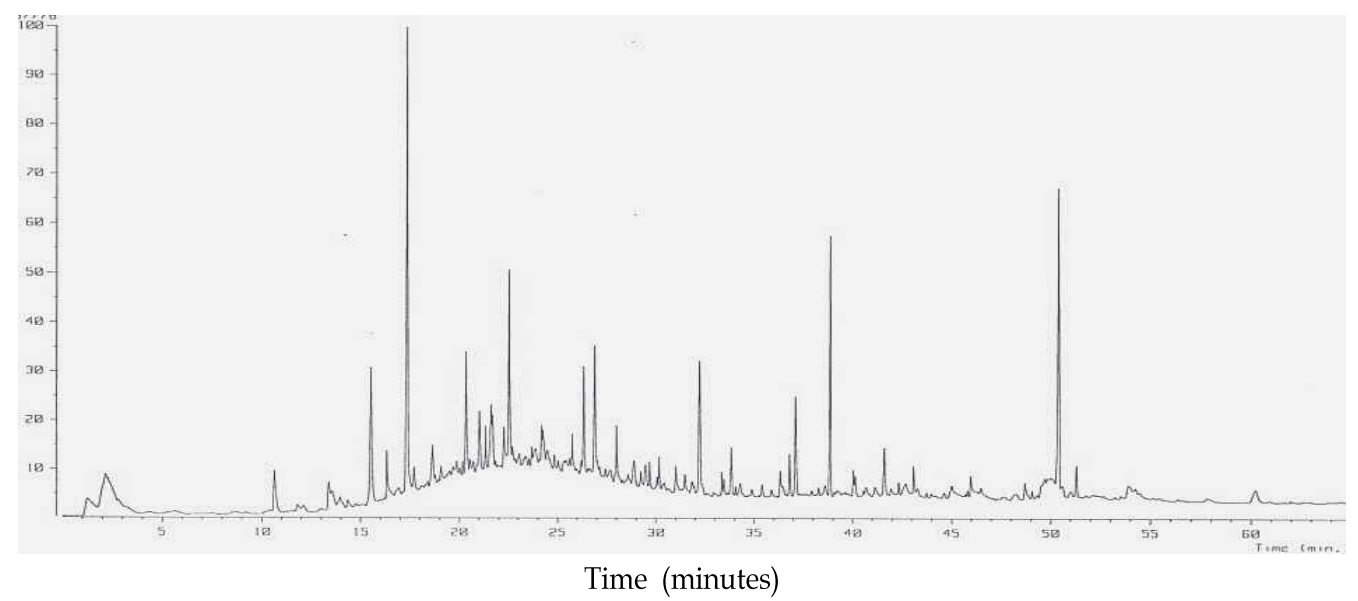

Fig. 3. Total ion chromatogram of headspace volatile components of Mideoduck muscle by solid-phase microextraction (SPME).

Table 3. Whole volatile compounds of Mideoduck muscle by solid-phase microextraction (SPME)

\begin{tabular}{cccl}
\hline RT & R.I. $^{\text {a }}$ & Conc. $^{\text {b }}$ & Compounds name $^{\mathrm{c}}$ \\
\hline 3 & 869 & 0.3 & Hexanal \\
4 & 1032 & 0.2 & Heptane \\
5 & 1198 & 3.4 & 1-Octanol \\
6 & 1230 & 1.1 & (Z)-4,5-Dimethylhex-2-en-4-ol \\
7 & 1260 & 31.6 & 1-Nonanol \\
8 & 1270 & 6.5 & 1-Decanol \\
11 & 1353 & 4.4 & 5-Decen-2-ol \\
16 & 1416 & 8.2 & 1-Tridecanol \\
24 & 1517 & 5.1 & 2,6-Bis(1,1-dimethylethyl)-4-methylphenol \\
26 & 1533 & 6.5 & 2,3-Diethyl-1,5,7-trimethoxyindenone \\
27 & 1557 & 7.6 & N-Butyl-4,9-decadien-2-amine \\
37 & 1735 & 4.1 & 1-(1-Hydroxycyclohexyl)-3,3-dimethyl-2-butanone \\
39 & 1757 & 0.2 & Cycloheptadecanol \\
41 & 1867 & 0.3 & (Z)-9-Octadecen-1-ol \\
42 & 1948 & 20.3 & (E)-2-Butenedioic acid dibutyl ester \\
47 & 2222 & 26.7 & Hepatadecanoic acid \\
\hline
\end{tabular}

${ }^{\mathrm{a}}$ Retention index on Supelcowax $320^{\mathrm{TM}}(30 \mathrm{~m} \times 0.25 \mathrm{~mm}$ i.d. $\times 0.25 \mu \mathrm{m}$ thickness, Supelco Co., USA) column.

${ }^{\mathrm{b}}$ Concentration $(\mu \mathrm{g} / \mathrm{g})$ of each compound was calculated as a relative content to cyclohexanol put in sample by extraction method $(70.3 \mu \mathrm{g})$ (factor=1.0).

'These compounds were tentatively identified by MS Library data (Wiley $275 \mathrm{~K}$. Hewlett-Packard Co., USA). 
장 높았으며, 이외에 주요 aldehyde류로서는 2,4-decadienal, tridecanal, tetradecanal, 1,13-tetradecadienal, hexadecanal 등 이 동정되었는데, 이들은 주로 고도불포화지방산의 산화분해 에 의해 생성된 것으로 보이며[11], ketone류와 더불어 감미 있는 달콤한 향기발현에 기여한다는 보고도 있다[5]. Cha 등 [6]에 의하면 수산물 중의 카르노닐류는 지방산화에 의해 형성 되는 것으로 보고되어 있다. Acid류는 4종 동정되었으며 특히 유리지방산은 트리글리세라이드의 일부가 장기간 저장되거나
가열 살균되거나 여러 공정을 거치는 동안 가수분해되어 형성 되는 물질로서 구린내로 느껴지기도 한다[19]. Hydrocarbon류 는 7종이 동정되었고, 함질소 화합물 등은 동정되지 않았다.

가열 향과는 달리 SPME 방법으로 추출 동정된 화합물은 미더덕 육 및 체액의 향을 그대로 반영한다고 할 수 있다. 육으 로부터 동정된 화합물을 Fig. 3 및 Table 3에 각각 나타내었다. 총 16종으로 alcohol류 9종, aldehyde류 1종, acid 류 1종, hydrocarbon류 1종, ester류 1종, amine류 1종, ketone류 2종으로

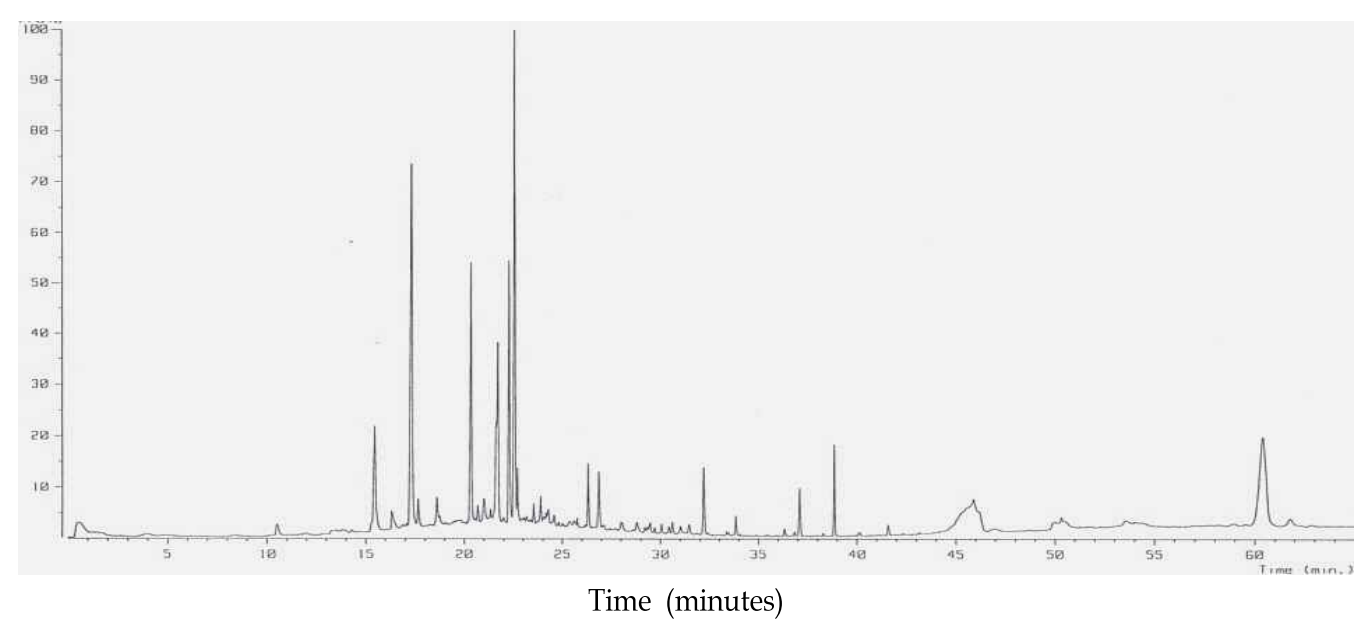

Fig. 4. Total ion chromatogram of headspace volatile components of Mideoduck fluid by solid-phase microextraction (SPME).

Table 4. Whole volatile compounds of Mideoduck fluid by solid-phase microextraction (SPME)

\begin{tabular}{cccl}
\hline RT & R.I. $^{\text {a }}$ & Conc. $^{\text {b }}$ & Compounds name $^{\text {c }}$ \\
\hline 3 & 869 & 0.2 & Hexanal \\
4 & 1032 & 0.1 & Heptane \\
5 & 1198 & 4.3 & 1-Octanol \\
6 & 1230 & 0.2 & (Z)-4,5-Dimethylhex-2-en-4-ol \\
7 & 1260 & 19.8 & 1-Nonanol \\
8 & 1270 & 1.5 & 1-Decanol \\
9 & 1300 & 16.4 & 1-Undecanol \\
11 & 1353 & 0.4 & 5-Decen-2-ol \\
13 & 1393 & 0.5 & 1-Dodecene \\
15 & 1405 & 18.6 & 2,4-Decadienal \\
16 & 1416 & 31.2 & Tridecanal \\
17 & 1421 & 1.2 & 1-Tridecanol \\
26 & 1533 & 1.8 & 2,3-Diethyl-1,5,7-trimethoxyindenone \\
27 & 1557 & 1.7 & N-Butyl-4,9-decadien-2-amine \\
37 & 1735 & 2.0 & 1-(1-Hydroxycyclohexyl)-3,3-dimethyl-2-butanone \\
39 & 1757 & 0.4 & Cycloheptadecanol \\
41 & 1867 & 1.6 & (Z)-9-Octadecen-1-ol \\
42 & 1948 & 3.8 & (E)-2-Butenedioic acid dibutyl ester \\
45 & 2120 & 9.9 & Pentadecanoic acid \\
47 & 2222 & 0.1 & Hepatadecanoic acid \\
\hline
\end{tabular}

${ }^{\mathrm{a}}$ Retention index on Supelcowax $320^{\mathrm{TM}}(30 \mathrm{~m} \times 0.25 \mathrm{~mm}$ i.d. $\times 0.25 \mu \mathrm{m}$ thickness, Supelco Co., USA $)$ column.

${ }^{\mathrm{b}}$ Concentration $(\mathrm{\mu g} / \mathrm{g})$ of each compound was calculated as a relative content to cyclohexanol put in sample by extraction method $(70.3 \mu \mathrm{g})$ (factor=1.0).

${ }^{\mathrm{c}}$ These compounds were tentatively identified by MS Library data (Wiley $275 \mathrm{~K}$. Hewlett-Packard Co., USA). 
다양한 형태를 함유하고 있었다. Alcohol 류 중에서는 1-nonanol이 $31.6 \mu \mathrm{g} / \mathrm{g}$, ester 중에서는 (E)-2-butenedioic acid dibutylester가 $20.3 \mathrm{\mu g} / \mathrm{g}$, acid류 중에서는 heptadecanoic acid가 $26.7 \mu \mathrm{g} / \mathrm{g}$ 으로 전체 함량의 $62.1 \%$ 를 차지하였다.

체액으로부터는 20종으로 alcohol류 9종, aldehyde류 3종, acid류 2종, hydrocarbon류 2종, ester류 1종, amine류 1종, ketone류 2종으로 육 추출액과 비슷한 구성을 보여주고 있었다. 1-Nonanol이 $19.8 \mu \mathrm{g} / \mathrm{g}$, 1-undecanol은 $16.4 \mu \mathrm{g} / \mathrm{g}$ 으로 alcohol류의 대부분을 차지하였고, aldehyde류에서는 2,4-decadienal이 $18.6 \mu \mathrm{g} / \mathrm{g}$, tridecanal이 $31.2 \mu \mathrm{g} / \mathrm{g}$ 으로 4 종 화합물이 전체 함량의 $74.3 \%$ 를 차지하여 이들이 미더덕 체액의 향을 나타내는 것으로 여겨진다. 육과는 달리 체액에서의 acid류 함량은 적은 것으로 나타났다.

\section{감사의 글}

본 연구는 해양수산부 수산특정연구개발사업(과제번호: MNF22004012-3-2-SB010)의 지원에 의하여 이루어졌으며, 이 에 감사드립니다.

\section{References}

1. Ahn, S. H., S. H. Jung, S. J. Kang, T. S. Jeong, and B. D. Choi. 2003. Extraction of glycosaminoglycans from Styela clava tunic. Korean J. Biotechnol. Bioeng. 18, 180-185.

2. Allen, D. H., J. Delohery, and G. Caker. 1987. Monosodium L-glutamate-induced asthma. J. Allergy Clin. Immund. 80, 530-537.

3. Cadwallader, K. R., H. H. Baek, H. Y. Chung, and M. W. Moody. 1994. Contribution of lipid-derived components to the flavor of alligator meat, pp. 186-195, In Ho, C. T. and T. G. Hartman (eds.), Lipids in Food Flavor. American Chemical Society, Washington DC.

4. Cha, Y. J., H. H. Baek, and T. C. Y. Hsieh. 1993. Volatile components in flavor concentrate from crayfish processing waste. J. Sci. Food Agric. 58, 239-243.

5. Cha, Y. J., K. R. Cadwallader, and H. H. Baek. 1992. Volatile flavor components in snow crab cooker effluent and effluent concentrates. J. Food Sci. 58, 525-529.

6. Cha, Y. J., W. J. Cho, and E. J. Jeong. 2006. Comparison of volatile flavor compounds in meat of the blue crab using V-SDE and SPME methods. J. Korean Fish Soc. 39, 441-446.

7. Choi, B. D. and C. T. Ho. 1995. Volatile compounds of ascidian, Halocynthia roretzi. J. Fish Soc. 28, 761-769.

8. Fujimoto, K., Y. Moyayama, and T. Kaneda. 1982. Mechanism of the formation of ascidian flavor in Halocynthia roretzi. Bull. Japan Soc. Sci. Fish 48, 1323-1326.

9. Jeong, E. J., W. J. Cho, and Y. J. Cha. 2008. Volatile flavor compounds in Omandungi (Styela plicata)-Doenjang (Soybean paste) soups and stew by cooking. J. Life Sci. 18, 1570-1577.

10. Jeong, E. J., W. J. Cho, and Y. J. Cha. 2008. Aroma-active compounds in Omandungi (Styela plicata)-Doenjang (Soybean Paste) stew. J. Korean Fish Soc. 41, 414-418.

11. Josephson, D. B. and R. C. Lindsay. 1987. Retro-aldol degradations of unsaturated aldehydes: Role in the formation of c4-heptenal from t2,c6-nanadienal in fish, oyster and flavors. J. Am Oil Chem Soc. 64, 132-138.

12. Jung, E. S., J. Y. Kim, E. J. Park, H. R. Park, and S. C. Lee. 2006. Cytotoxic effects from Styela clava against human cancer cell lines. J. Korean Soc. Food Sci. Nutr. 35, 823-827.

13. Kim, J. J., S. J. Kim, S. H. Kim, H. R. Park, and S. C. Lee. 2006. Antioxidant and anticancer activities of extracts from Styela clava according to the processing methods and solvents. J. Korean Soc. Food Sci. Nutr. 35, 278-283.

14. Kim, J. J., S. J. Kim, S. H. Kim, H. R. Park, and S. C. Lee. 2005. Antioxidant and anticancer activities of extracts from Styela plicata. J. Korean Soc. Food Sci. Nutr. 34, 937-941.

15. Kusaka, H., H. Narita, K. Iwata, and S. Ohta. 1983. Gas liquid chromatographic determination of flavor component from ascidian. Bull. Japan Soc. Sci. Fish 49, 617-620

16. Loda, M. N., J. S. Lee, S. J. Kang, and B. D. Choi. 2006. Seasonal variation in the nutritional content of Mideodeok Styela clava. J. Fish Sci. Technol. 9, 49-56.

17. Nikerson, G. B. and S. T. Likens. 1996. Gas chromatographic evidence for occurrence of hop oil components in beer. $J$. Chromatography 21, 1-5.

18. Park, S. M., B. B. Lee, Y. M. Hwang, and S. C. Lee. 2006. Quality properties of fish paste contaning Styela clava. J. Korean Soc. Food Sci. Nutr. 35, 908-911.

19. Reineccius, G. 2006. Changes in food flavor due to processing, pp. 108-143, In Reineccius, G. (ed.), Flavor Chemistry and Technology. CRC Press, Boca Raton, FL.

20. Reineccius, G. 2006. Off-Flavors and taints in foods, pp. 166-200, In Reineccius, G. (ed.), Flavor Chemistry and Technology. CRC Press, Boca Raton, FL.

21. Rha, Y. A. 2005. Trend and future of natural seasoning in Korea. Proceeding of 2005 Culinary Society of Korean Academy. October 89-97. Seoul, Korea.

22. Satoh, N. and T. Deno. 1984. Periodic appearance and disappearance of microvilli associated with cleavage cycles in the egg of the ascidian, Halocynthia roretzi. Develop. Biol. 102, 488-492.

23. Seo, B. Y., E. S. Jung, J. Y. Kim, E. J. Park, H. R. Park, S. C. Lee, and E. J. Park. 2006. Effect of acetone extract from Styela clava on oxidative DNA damage and anticancer activity. J. Korean Soc. Appl. Biol. Chem 49, 227-232. 


\section{초록 : 미더덕의 향기 성분}

최병대* · 오봉세 ${ }^{1} \cdot$ 강석중 $^{2}$

(경상대학교 해양식품공학과, ${ }^{1}$ 국립수산과학원, ${ }^{2}$ 경상대학교 해양생명과학과)

미더덕 육과 체액을 이용한 천연 조미료의 제조를 위하여 본래의 향과 가열에 따른 변화를 비교해보기 위하여 $\mathrm{SDE}$ 법과 $\mathrm{SPME}$ 법으로 미더덕 향기성분을 분석하였다. $\mathrm{SDE}$ 추출법으로 얻어진 미더덕 육에 함유된 주요 성분으 로서는 hexanal $371.3 \mu \mathrm{g} / \mathrm{g}$, 1-tridecanol $80.1 \mu \mathrm{g} / \mathrm{g}$, (Z)-4,5-dimethyhex02-en-4-ol 72.1 $\mathrm{gg} / \mathrm{g}$ 등이 있었고, 그 외 다량의 alcohol, aldehydes 및 acids가 얻어졌다. SDE 추출법으로 얻어진 alcohol은 농도도 높았지만 미더덕 육 향기성분의 주체가 되는 것으로 나타났다. SPME 추출법으로 얻어진 미더덕 육에는 9종의 alcohols, 1 종의 acid, 1 종의 aldehyde, 1 종의 hydrocarbon, 1 종의 ester, 1 종의 amine 및 2종의 ketones이 포함되어 있었다. 이들 중 함량이 가장 높았으며 그 중 1-nonanol, 1-decanol 및 1-tridecanol이 주성분이었다. SPME법으로 얻어진 향기성분 중 1-nonanol $31.6 \mu \mathrm{g} / \mathrm{g}$, (E)-2-butanoic acid dibutylester $20.3 \mu \mathrm{g} / \mathrm{g}$ 및 heptadecanoic acid $26.7 \mu \mathrm{g} / \mathrm{g}$ 으로 전체 향기성분 추출물의 $62.1 \%$ 를 차지하였다. 따라서 SPME법으로 얻어진 향기성분이 SDE법보다 추출효율은 낮았지 만 원래 향에 가까운 것으로 나타났다. 